\title{
Indirect Prediction of Welding Fume Diffusion inside a Room Using Computational Fluid Dynamics
}

\author{
Sujit Dahal ${ }^{1,2}$, Taehyeung Kim ${ }^{2, *}$ and Kwangseog Ahn ${ }^{3}$ \\ 1 Department of Eco-Friendly Offshore Plant FEED Engineering, Changwon National University, \\ Changwon 641-773, Korea; sjtdahal7@gmail.com \\ 2 Department of Environmental Engineering, Changwon National University, Changwon 641-773, Korea \\ 3 Department of Occupational \& Environmental Safety \& Health, University of Wisconsin-Whitewater, \\ 809 W. Starin Road, Whitewater, WI 53190, USA; ahnk@uww.edu \\ * Correspondence: thkim@changwon.ac.kr; Tel.: +82-3876-7565
}

Academic Editor: Robert W. Talbot

Received: 13 April 2016; Accepted: 20 May 2016; Published: 25 May 2016

\begin{abstract}
Welding is an important and widely used process in the manufacturing and maintenance of various works involving metals and alloys. While welding has broad applications, the welding fume generated during the process has impacts on workers' health, which needs to be addressed. One of the major steps that can be undertaken to take care of this issue is the use of ventilation, which requires knowledge of characteristics and dispersion of the welding fume in the workers' breathing zone. It is difficult to assess welding fume dispersion from manual measurement due to numerous welding processes and sufficient data requirement. Numerical prediction of welding fume is dubious due to several errors. This paper considers the use of numerically predicted $\mathrm{CO}_{2}$ concentrations to indirectly predict welding fume distribution in workshops. This is based on the assumption that if the particles are sufficiently small size, they follow the diffusion pattern of gases. Experiments are carried out in a room with an opening and a welding fume generation system for measurement of $\mathrm{CO}_{2}$ and fume diffusion. The results show high possibility of predicting welding fume concentration based on Computational Fluid Dynamics (CFD) simulated $\mathrm{CO}_{2}$ concentration with a correlation coefficient of 0.74 .
\end{abstract}

Keywords: CFD; health effects of welding fume; indirect prediction; ventilation; welding fume dispersion

\section{Introduction}

Welding technology is a necessary process in the construction and maintenance of industries, large structures, vehicles, ships, offshore structures, and a number of practices involving metal works $[1,2]$. Nowadays, some of the welding is operated with the help of machines and robots but most is still carried on manually for precision and quality of work. However, the disadvantage of manual welding is that the fumes produced during the process have a great impact on workers' health [1]. These fumes consist of powders of different solid substances like $\mathrm{Cu}, \mathrm{Ni}, \mathrm{Zn}$, etc. with sizes ranging from 1 to $7 \mu \mathrm{m}$. Along with the fumes, different gases such as $\mathrm{CO}_{2}, \mathrm{CO}, \mathrm{NO}_{\mathrm{x}}, \mathrm{SO}_{\mathrm{x}}, \mathrm{O}_{3}$, etc., and numerous organic pollutants are also produced during the welding process [3]. The gases are formed and emitted due to the presence of extremely high temperature, ultraviolet radiation arising from the arc, and reactions of hot base metal with atmospheric $\mathrm{O}_{2}$ and $\mathrm{N}_{2}$. However, appearance of $\mathrm{CO}_{2}$ is an exception to those factors because it is generally used as a shielding gas in many welding processes [4]. Shielding gas is used in welding to protect the weld pool from oxidization in ambient air and to reduce fume emission [5]. Some of the examples of welding techniques using shielding gas are gas metal arc welding, electro-gas welding, laser beam welding, plasma arc cutting, etc. Among these techniques, 
gas metal arc welding is the most common and widely employed technique for joining metal and a vast range of alloys [6], and it uses $\mathrm{Ar}, \mathrm{He}, \mathrm{O}_{2}$, and $\mathrm{CO}_{2}$ as major shielding gases. Ar and $\mathrm{He}$, being inert gases, do not cause major health and environmental risks, and generally produce good-quality welding, but are approximately ten times more expensive then $\mathrm{CO}_{2}$. For welding of steel structures, either $100 \% \mathrm{CO}_{2}$ or combination of $\mathrm{CO}_{2}$ and these inert gases can be used. The additional advantage of using $\mathrm{CO}_{2}$ with other pure gases during welding of metals and alloys is to improve arc stability, minimize undercut, reduce porosity, and improve the appearance of the weld [2].

This kind of gas shielded welding is frequently performed in enclosed compartments and rooms such as in shipbuilding industries where the welder has exposure to a high concentration of fumes [7]. Gomes et al. did assessments of airborne ultrafine particles generated from tungsten inert gas, metal active gas, and friction stir welding, and found that all these processes emitted significant concentrations of ultrafine particles which were deposited in the lungs of exposed workers [8,9]. Inhalation of these fumes and gases have a great effect on lung function and causes acute as well as chronic diseases like lung cancer, infection, metal fume fever, etc. Hence, it is very essential to protect workers from welding fume exposure $[10,11]$. Reduction of welding fumes from workers zone is generally achieved by three processes: reduction at the source by changes in process and conditions, use of ventilation and exhausts, and use of a device for personal protection [1]. After reduction at the source, there is still a significant amount of fumes released which should be removed by employing a ventilation method. Welding fume generally consists of ultra-fine and fine particles ranging from a diameter of less than approximately 0.1 to $3 \mu \mathrm{m}$ [12], which are difficult to remove by natural ventilation because these particles are easily influenced by the complex airflow pattern of the room [13]. The most widely-used ventilation method for control of these contaminants is local exhaust ventilation because it is more effective compared to general ventilation and dilution ventilation [14]. The design of local exhaust ventilation system to efficiently capture most of the fugitive fumes requires knowledge of concentration pattern of the dust near the contaminant source and transport of fumes from their source of origin to exhaust. Transport and concentration of fume is affected by factors like exhaust openings, ambient air currents, momentum of contaminant source, mobility of worker, etc. [15]. It is a difficult task to manually investigate transport pattern and concentration variation through experiments because sufficient numbers of measurements for more than 80 different welding and associated processes are difficult to achieve [16].

Instead of carrying out experiments, numerical methods can be used to predict the concentration of the fume particles, depending on provided conditions and related factors. Based on numerical methods, research has been done for prediction of particle concentration using Computational Fluid Dynamics (CFD) but the simulated results frequently have some divergence from the experimental results. The errors are due to limitations on the predictive methods, which do not take some factors such as particle size distribution and particle rebounding process into consideration [17]. Unlike modeling of particulate matter, CFD has been used in many previous studies with good performance to predict $\mathrm{CO}_{2}$ concentration profile and dispersion in a single room using natural as well as mechanical ventilation $[18,19]$. Lambert et al. compared the measured and CFD simulated values of $\mathrm{CO}_{2}$ decay in a controlled environment and found that the percent error between computational and experimental data was as low as 5.2\% and concluded CFD as an effective tool to study ventilation behaviors [20].

The purpose of this study is to simulate the diffusion of $\mathrm{CO}_{2}$ and find some analogy to support utility of indirect prediction of welding fume concentration. This conjecture is based on the theory that if the particles are in range of sub micrometer level, their motion properties follow the diffusion rules of gases i.e., Brownian diffusion for movement in the air [21,22]. The initial part of the study is conducting measurement of welding fume particle size to find out if the majority of particles belong to sub micrometer range, which is followed by further experiments. The present work is directed towards the comparison of welding fume distribution measured inside the room and $\mathrm{CO}_{2}$ distribution simulated using CFD. If a satisfactory correlation between these two components is achieved, it provides an opportunity to formulate a basis for further studies related to this aspect. 


\section{Methodology}

\subsection{Experimental Setup}

The physical model is a room $(\mathrm{L} \times \mathrm{W} \times \mathrm{H}=2900 \mathrm{~mm} \times 2800 \mathrm{~mm} \times 2200 \mathrm{~mm})$ with a single opening $(\mathrm{W} \times \mathrm{H}=600 \mathrm{~mm} \times 800 \mathrm{~mm})$ as shown in Figure 1. The welding apparatus is set up at the corner of the room, and it consists of a HIC 500c welder, welding table, base metal $(\mathrm{L} \times \mathrm{B} \times \mathrm{H}=$ $400 \mathrm{~mm} \times 400 \mathrm{~mm} \times 18 \mathrm{~mm}$ ), KS D0062 welding torch, and $\mathrm{CO}_{2}$ gas cylinder. The welding system is automated, and the welding conditions are set as follows: (1) arc voltage $=38 \mathrm{~V}$; (2) welding speed $=$ $0.6 \mathrm{~m} / \mathrm{min}$; (3) wire diameter $=1.2 \mathrm{~mm}$; (4) wire speed $=70 \mathrm{~mm} / \mathrm{s}$; (5) welding current $=350 \mathrm{~A}$; and (6) shield gas flow $=30 \mathrm{~L} / \mathrm{min}$. The configuration of the welding process is shown in Figure 1. Figure 2 displays five points, each at the height of $600 \mathrm{~mm}$ (lower part) and $1600 \mathrm{~mm}$ (upper part), to imitate the stature of a welder working in sitting and standing positions, respectively. The placement of the measurement points is shown in Figure 3 where four points are in the corners and one point is in the center of the room. These points are selected to measure size and number of welding fume particles, welding fume concentration and $\mathrm{CO}_{2}$ concentration. An exhaust fan (Model: MJVF-40, MJ AIRTECH CO., Ltd. Seoul, Korea) with maximum flow rate of $40 \mathrm{~m}^{3} / \mathrm{min}$ is used to ventilate the room.

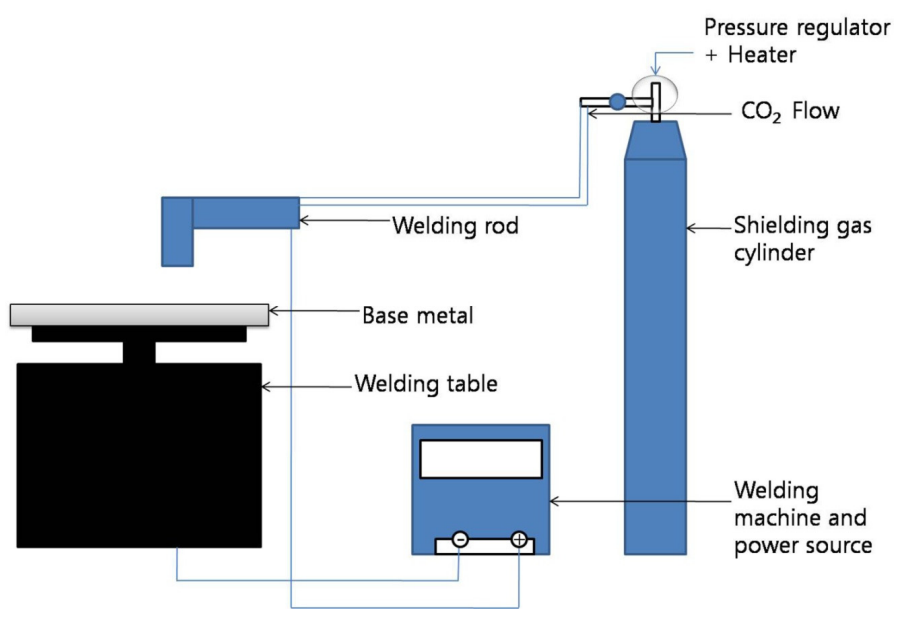

Figure 1. Schematic diagram of welding apparatus setup.

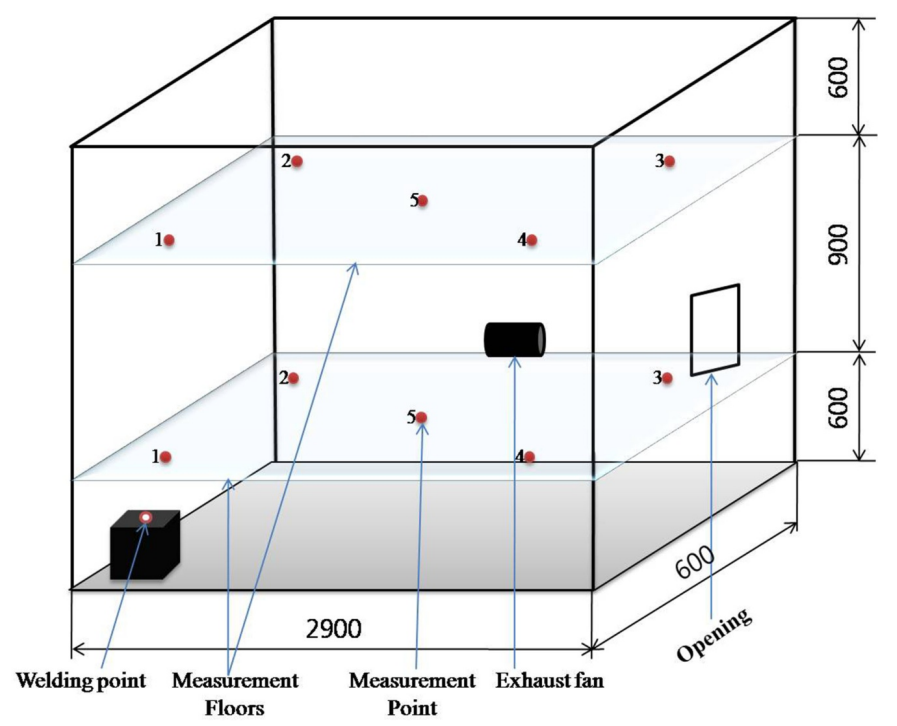

Figure 2. Schematic diagram of experimental setup and measurement points. 


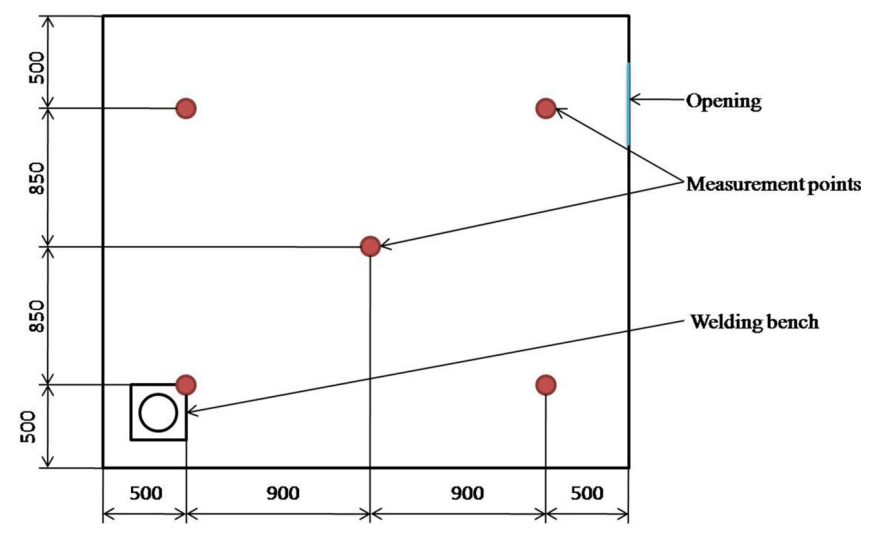

Figure 3. Top view of the model with measurement points.

\subsection{Field Measurement}

Experiments are carried out to measure the number and size of welding fume, concentration of welding fume and concentration of $\mathrm{CO}_{2}$ inside the room. Initially, the number and size of welding fume particles is measured using MET ONE 237B Portable Air Particle Counter (Hach Company, Loveland, CO, USA). The base metal is welded using an automated welding apparatus with continuous generation of fumes, and all the measurements are done $10 \mathrm{~min}$ after the commencement of the apparatus. The particle counter is operated for $5 \mathrm{~min}$ at a flow rate of 2 Liters per minute and six size channels, i.e., $0.3,0.5,0.7,1,2$, and $5 \mu \mathrm{m}$ are used to measure the number of particles of each size per $10 \mathrm{~L}$ of air sample. Before running the welding instrument and subsequent measurements, the particle counter is used to measure initial particle count in each size range inside the room. This background measurement of particle count is deducted from the total count of welding fume particles in each size range, and the results are reported. $\mathrm{CO}_{2}$ is measured at the ten measurement points using GrayWolf portable DirectSense IAQ meter (GrayWolf Sensing Solutions, Shelton, CT, USA) with $\mathrm{CO}_{2}$ measuring accuracy of $\pm 3 \%$ rdg or $\pm 50 \mathrm{ppm}$, which displays the measured values in ppm in the monitor. Real-time monitoring of $\mathrm{CO}_{2}$ is conducted 10 minutes after kickoff of the welding apparatus at all 10 measurement points. Gravimetric method is used to measure the weight of welding fume particles at all measurement points, and the measured weight is converted into concentration at each point. The welding fume concentration measuring system is operated at a flow of $2 \mathrm{~L} / \mathrm{min}$ for an hour and consists of a Personal Air Sampler (Model 224-PCXR4, SKC Inc., Eighty Four, PA, USA), Polyvinyl Chloride filter paper (pore size $=5 \mu \mathrm{m}$, diameter $=37 \mathrm{~mm}$ : SKC Inc., Eighty Four, PA, USA), and a precision analytical balance (Sartorius R 160 D, Elk Grove, IL, USA). Three separate measurements are conducted for both welding fume concentration and $\mathrm{CO}_{2}$ concentration, and the average of these measurements is used for comparison with simulated concentration $\mathrm{CO}_{2}$.

\subsection{CFD Simulation}

Commercially available CFD software ANSYS Airpak 3.0.16 (Fluent Inc., Lebanon, NH, USA) is used in this study to predict the $\mathrm{CO}_{2}$ concentration distribution in the room. Airpak is one of the most acceptable softwares to simulate indoor air quality which incorporates the powerful solver FLUENT [23]. Airpak uses FLUENT to solve turbulent flow equations based on finite volume method. Equations of conservation of energy, mass and momentum of incompressible air are solved by FLUENT to find the solution of the model. The two-equation $\mathrm{K}-\varepsilon$ turbulence model is used to solve turbulent flow conditions. There is a presence of mixed convection in the room due to the occurrence of both natural and forced convection. Natural convection is caused by buoyancy forces due to density differences in different parts of the room. The density difference is mainly caused by high temperature gas supplied into the building (i.e., $\mathrm{CO}_{2}$ temperature $=600^{\circ} \mathrm{C}, \mathrm{CO}_{2}$ flow $=0.03 \mathrm{~m}^{3} / \mathrm{min}, \mathrm{CO}_{2}$ flow diameter $=0.2 \mathrm{~cm}$, and $\mathrm{CO}_{2}$ velocity $=0.33 \mathrm{~m} / \mathrm{s}$ at welding point). Density gradient is not only caused by temperature gradient, but other factors are also associated with it. But for this study, 
density gradient due to temperature differences from heat sources is only taken into consideration as the effects caused by natural convection are far lower than the effects caused by forced convection. Forced convection occurs due to a ventilation system, i.e., an exhaust fan with airflow of $20 \mathrm{~m}^{3} / \mathrm{min}$. A fine mesh of hexa-unstructured geometry is used to discretize the domain. A grid independency test is performed using one coarse and two finer meshes. The fine mesh finally generated consists of 1.1 million cells. The 3-D model developed in Airpak with the same geometries and features as the physical setup is shown in Figure 4.

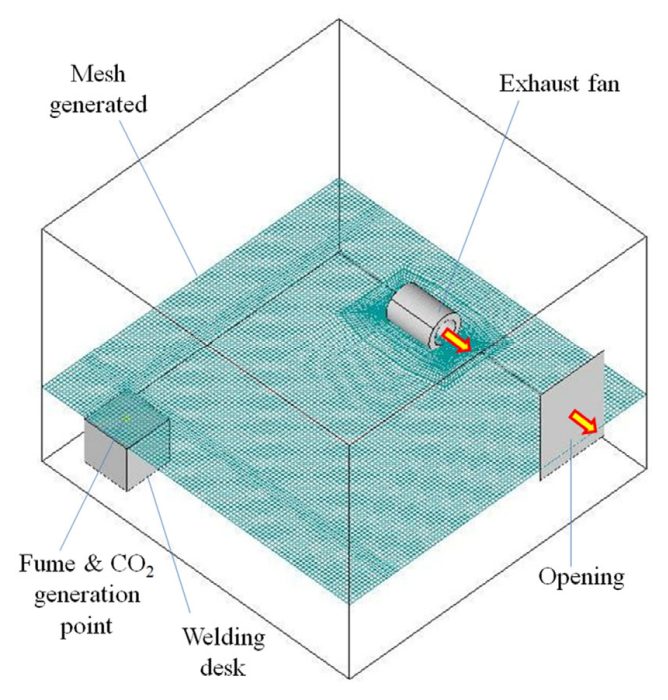

Figure 4. Model and mesh generation in Airpak.

\section{Results and Discussion}

\subsection{Welding Fume Particle Size Distribution}

Figure 5 shows the variation in welding fume particle size in the room. The respective particle count at the upper (1600 $\mathrm{mm}$ height) and lower $(600 \mathrm{~mm}$ height $)$ sections of the experimental room is shown in Table S1. The count presented in Table S1 is the result of deducting background measurement from the total measurement in each size range. From Figure 5, it is evident that most of the particles' sizes are less than $0.5 \mu \mathrm{m}$ and about $99.6 \%$ of the particles have a size less than $1 \mu \mathrm{m}$ (sub micrometer), which is the size that acts as gases during diffusion. Therefore, this reveals a possibility that welding fume particles and $\mathrm{CO}_{2}$ used as shielding gas emitted at the same point source in this study might have similar spread over the room. To explain this theory, a comparison is made between the concentrations of both welding fume and $\mathrm{CO}_{2}$ at the same points.

Welding Fume particle size distribution

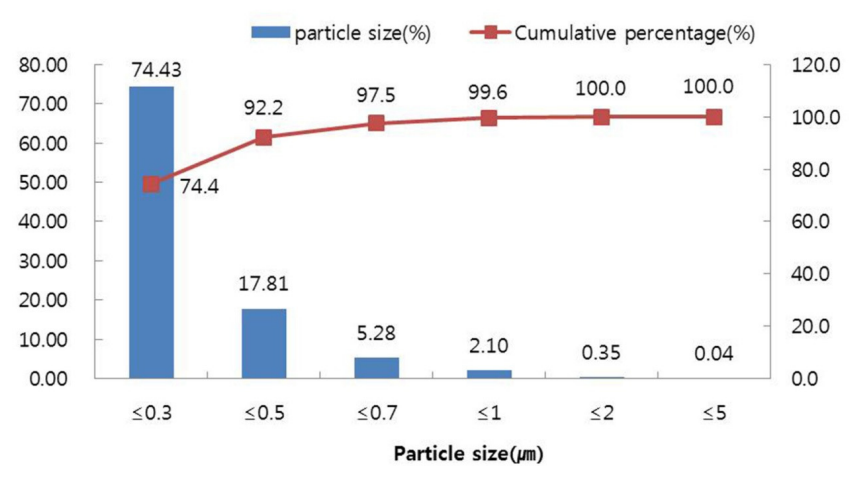

Figure 5. Size distribution of welding fume particles (\%). 


\subsection{Measured and Simulated Concentration of Welding Fume and $\mathrm{CO}_{2}$}

The results of measured concentration of welding fume, measured $\mathrm{CO}_{2}$, and simulated $\mathrm{CO}_{2}$ at ten measurement points inside the room are shown in Figures 6-8 respectively. Although the concentration units for welding fume and $\mathrm{CO}_{2}$ are different, the similarity of pattern among three graphs is certainly evident. Further reasoning of these results is done using regression analysis to find correlation that exists between the species.

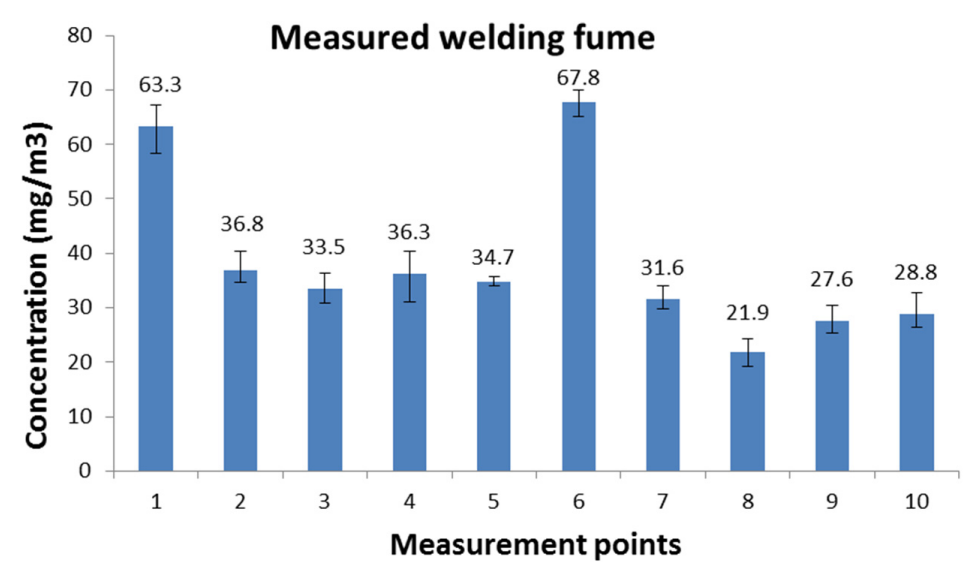

Figure 6. Concentration of measured welding fume at ten measurement points.

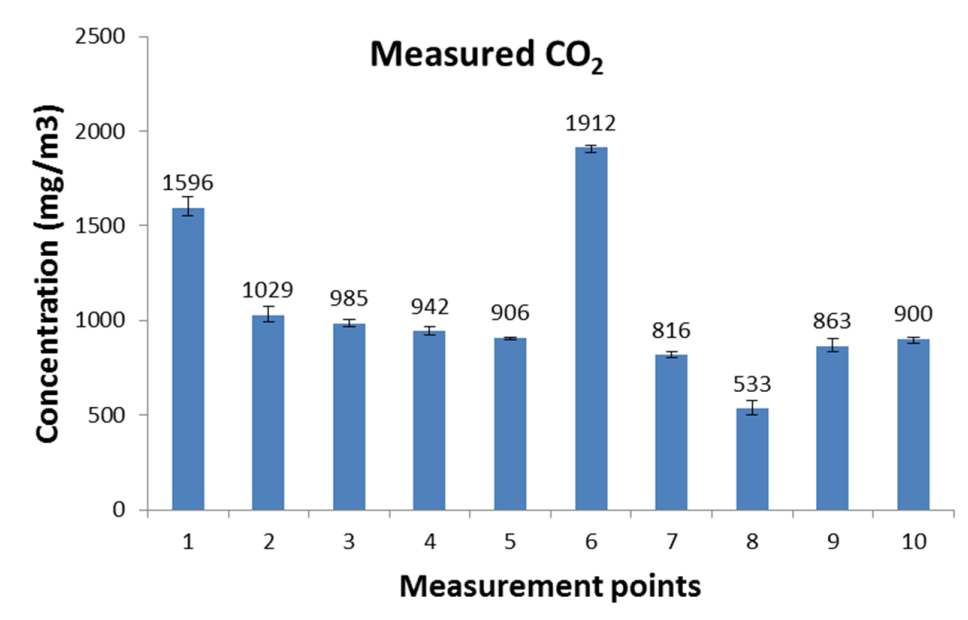

Figure 7. Concentration of measured $\mathrm{CO}_{2}$ at ten measurement points.

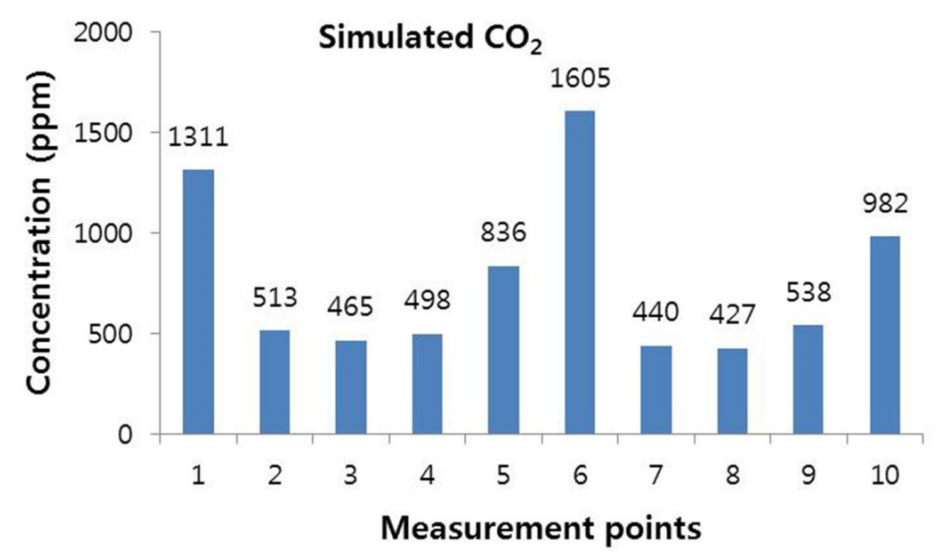

Figure 8. Concentration of simulated $\mathrm{CO}_{2}$ at ten measurement points. 


\subsubsection{Measured Welding Fume $v$ s. Measured $\mathrm{CO}_{2}$ Concentrations}

The $R^{2}$ (coefficient of determination) value of 0.96 between measured $\mathrm{CO}_{2}$ and measured welding fume concentrations as shown in the regression plot as shown in Figure 9 explains that the concentration of welding fume particles and $\mathrm{CO}_{2}$ spread in the room atmosphere is very similar. In other words, this shows that both the species have similar patterns of distribution in the room. As the correlation is higher, the error during prediction is lower, which contributes to better prediction accuracy.

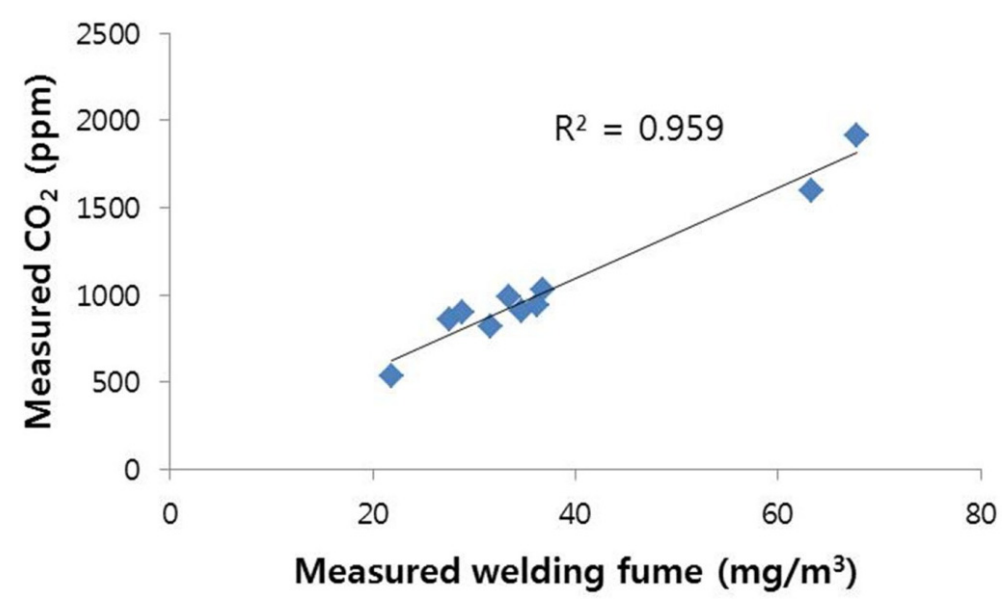

Figure 9. Correlation of measured welding fume and measured $\mathrm{CO}_{2}$.

\subsubsection{Measured $\mathrm{CO}_{2}$ vs. Simulated $\mathrm{CO}_{2}$ Concentrations}

Figure 10 is the regression plot of measured and simulated $\mathrm{CO}_{2}$ with a $R^{2}$ value of 0.78 . This is a relatively high coefficient value, which supports that the prediction of $\mathrm{CO}_{2}$ concentration through computer simulation is finely accurate. Hence, in an arc welding workshop, which uses $\mathrm{CO}_{2}$ as a shielding gas, it is possible to predict the concentration distribution of $\mathrm{CO}_{2}$ with the help of computer simulation.

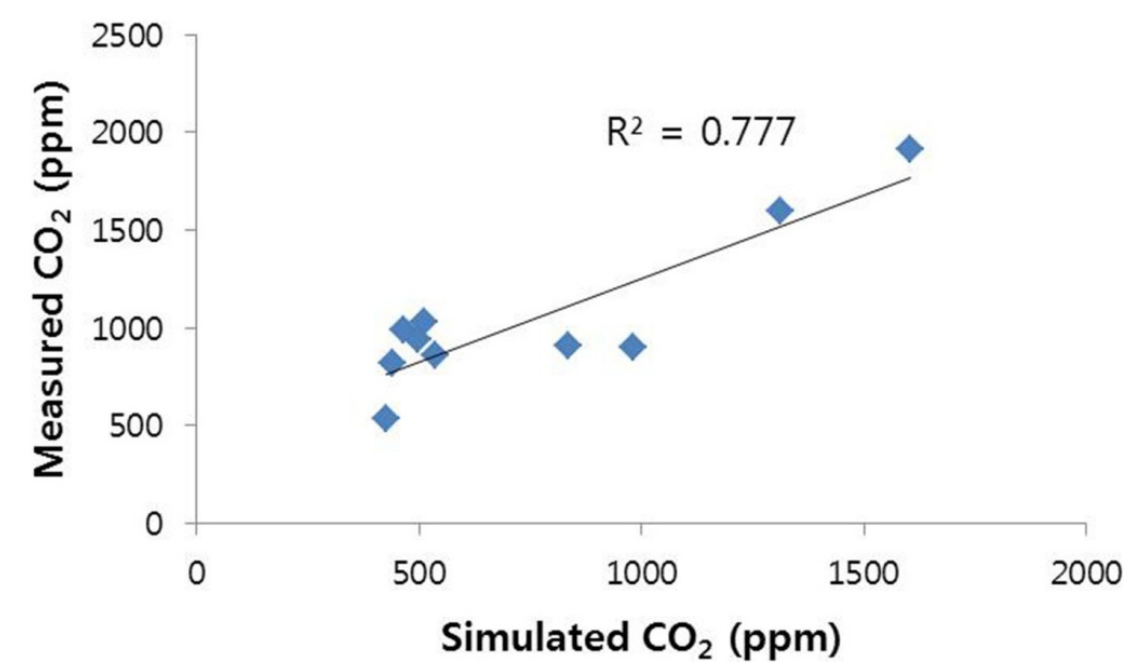

Figure 10. Correlation of simulated $\mathrm{CO}_{2}$ and measured $\mathrm{CO}_{2}$.

\subsubsection{Measured Welding Fume vs. Simulated $\mathrm{CO}_{2}$ Concentrations}

The comparison of measured welding fume and simulated $\mathrm{CO}_{2}$ concentrations portrays a $R^{2}$ value of 0.74 as shown in Figure 11. In other words it can be implied that change in concentration of measured welding fume could be predicted through simulated $\mathrm{CO}_{2}$ with accuracy of around $74 \%$. 
This is also a relatively high value of coefficient of determination, and it supports that there is a possibility of achieving a meaningful prediction of welding fume concentration indirectly through $\mathrm{CO}_{2}$ simulated results.

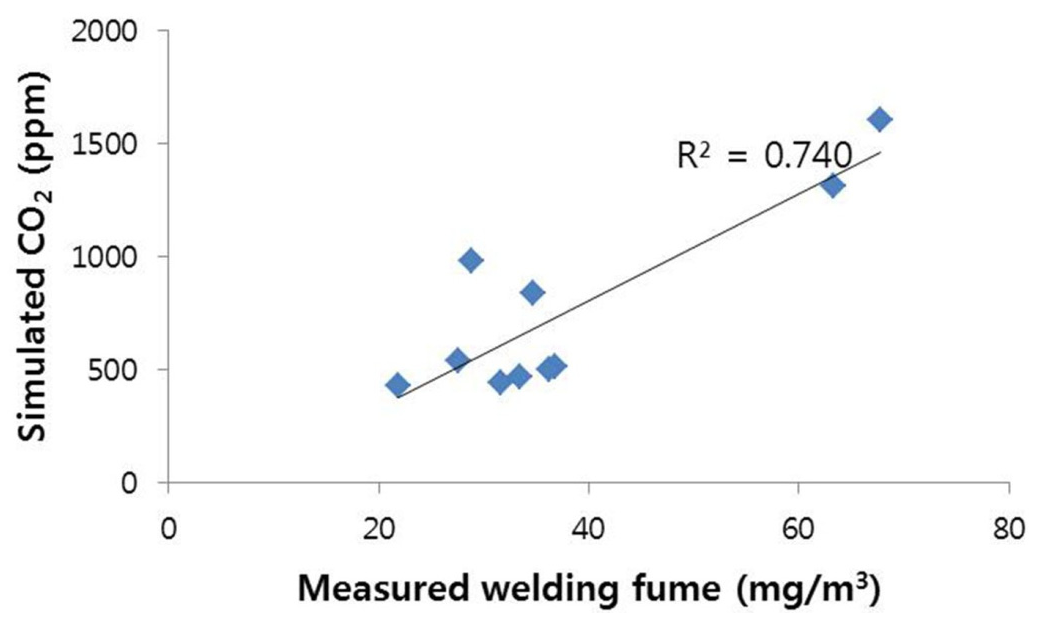

Figure 11. Correlation of simulated $\mathrm{CO}_{2}$ and measured welding fume.

\section{Conclusions}

This paper presents a possibility of an alternative method for prediction of welding fume concentration inside a closed room with forced ventilation, i.e., by use of simulated $\mathrm{CO}_{2}$ concentration. The research was conducted by measuring $\mathrm{CO}_{2}$ and welding fume concentration, and comparing it with predicted $\mathrm{CO}_{2}$ concentration. The extent of their relationship was evaluated using regression analysis. The squared correlation coefficient $\left(R^{2}\right)$ of the experimental $\mathrm{CO}_{2}$ and welding fume concentration is very high $\left(R^{2}=0.96\right)$, which means the behaviors of welding fume and the $\mathrm{CO}_{2}$ used as shielding gas are very similarly spread in the atmosphere. Comparison of the relationship between predicted $\mathrm{CO}_{2}$ with measured $\mathrm{CO}_{2}$ and welding fume concentration shows $R^{2}$ values of 0.77 and 0.74 respectively, which are also relatively high values and back a meaningful prediction. Based on the results, it can be established that the numerical simulations are sufficiently useful to indirectly calculate appropriate welding fume emissions in the case that proper measurement technique and instrument is unavailable for direct measurement. It is possible to explain this compatibility. The diffusion of fume particles and other gases is comparable as measurement of particle size showed that more than $99.5 \%$ of fume particle size is below $1 \mu \mathrm{m}$ and that they tend to follow the diffusion pattern of gases. As this study was not aimed in developing a model for prediction of welding fume, but to determine the possibility of indirect prediction based on diffusion characteristics, future research should be directed towards unearthing the relationship of these two species by changing model parameters and verifying it by using adequate numbers of measurements. Further experiment and simulation can also be applied with complex building setup to illustrate the significance of this method in more realistic conditions.

Supplementary Materials: The following is available online at http:/ /www.mdpi.com/2073-4433/7/6/74/s1. Table S1: Number and diameter of welding fume particles.

Acknowledgments: This research was financially supported by Changwon National University, South Korea in 2014-2015. The authors also wish to thank the editor and anonymous reviewers for valuable suggestions.

Author Contributions: Sujit Dahal was involved in literature review experimental works, conduction of CFD simulation, analysis of the results, and writing the manuscript. Kwangseog Ahn contributed to the concept and methodology of the research and assisted in reviewing and editing the manuscript. Taehyeung Kim designed the concept and methodology of the research, supervised the experimental works and analysis of results and assisted in reviewing and editing the manuscript. All authors have read and approved the final manuscript.

Conflicts of Interest: The authors declare no conflict of interest. 


\section{References}

1. Escala, S.; Nooij, M.; Quintino, L. Economically welding in a healthy way. In Proceedings of the First South-East European Welding Congress, Timisoara, Romania, May 2006; pp. 244-251.

2. Hashmi, S.; Batalha, G.; van Tyne, C.; Yilbas, B. Comprehensive Materials Processing; Elsevier: Oxford, UK, 2014; pp. 3-71.

3. Amza, G.; Dobrotă, D.; Groza Dragomir, M.; Paise, S.; Apostolescu, Z. Research on environmental impact assessment of flame oxyacetylene welding processes. Metalurgija 2013, 52, 457-460.

4. Fume and Gases. Available online: http://www.webcitation.org/6gjMEC5zn (accessed on 13 April 2016).

5. Suban, M.; Tušek, J. Dependence of melting rate in MIG/MAG welding on the type of shielding gas used. J. Mater. Proc. Technol. 2001, 119, 185-192. [CrossRef]

6. Kielhorn, W.H.; Adonyi, Y.; Holdren, R.L.; Horrocks, R.C.; Nissley, N.E. Survey of Joining, Cutting, and Allied Processes; AWS Welding Handbook: New York, NY, USA, 2001; p. 50.

7. Shibata, N.; Tanaka, M.; Ojima, J.; Iwasaki, T. Numerical simulations to determine the most appropriate welding and ventilation conditions in small enclosed workspace. Ind. Health 2000, 38, 356-365. [CrossRef] [PubMed]

8. Gomes, J.F.; Albuquerque, P.C.; Miranda, R.M.; Santos, T.G.; Vieira, M.T. Comparison of deposited surface area of airborne ultrafine particles generated from two welding processes. Inhal. Toxicol. 2012, 24, 774-781. [CrossRef] [PubMed]

9. Gomes, J.F.P.; Albuquerque, P.C.S.; Miranda, R.M.M.; Vieira, M.T.F. Determination of airborne nanoparticles from welding operations. J. Toxicol. Environ. Health 2012, 75, 747-755. [CrossRef] [PubMed]

10. Antonini, J.; Lewis, A.; Roberts, J.; Whaley, D. Pulmonary effects of welding fumes: Review of worker and experimental animal studies. Am. J. Ind. Med. 2003, 43, 350-360. [CrossRef] [PubMed]

11. Popović, O.; Prokić-Cvetković, R.; Burzić, M.; Lukić, U.; Beljić, B. Fume and gas emission during arc welding: Hazards and recommendation. Renew. Sustain. Energy Rev. 2014, 37, 509-516. [CrossRef]

12. Oprya, M.; Kiro, S.; Worobiec, A.; Horemans, B.; Darchuk, L.; Novakovic, V.; Ennan, A.; van Grieken, R. Size distribution and chemical properties of welding fumes of inhalable particles. J. Aerosol Sci. 2012, 45, 50-57. [CrossRef]

13. Chang, T.; Kao, H.; Hsieh, Y. Numerical study of the effect of ventilation pattern on coarse, fine, and very fine particulate matter removal in partitioned indoor environment. J. Air Waste Manag. Assoc. 2007, 57, 179-189. [CrossRef] [PubMed]

14. The National Institute for Occupational Safety and Health (NIOSH). Welding, Fumes and Gases; Australian Government Publishing Service: Canberra, Australia, 1990; p. 32.

15. Kulmala, I. Advanced Design of Local Ventilation Systems; Technical Research Centre of Finland: Espoo, The Netherlands, 1997; p. 80.

16. The National Institute for Occupational Safety and Health (NIOSH). Criteria for a Recommended Standard: Welding, Brazing, and Thermal Cutting. Available online: http://www.cdc.gov/niosh/docs/88-110/pdfs/ 88-110.pdf (assessed on 23 May 2016).

17. Lu, W.; Howarth, A.; Adam, N.; Riffat, S. Modelling and measurement of airflow and aerosol particle distribution in a ventilated two-zone chamber. Build. Environ. 1996, 31, 417-423. [CrossRef]

18. Karthikeyan, C.; Samuel, A. $\mathrm{CO}_{2}$-dispersion studies in an operation theatre under transient conditions. Energy Build. 2008, 40, 231-239. [CrossRef]

19. Kavgic, M.; Mumovic, D.; Stevanovic, Z.; Young, A. Analysis of thermal comfort and indoor air quality in a mechanically ventilated theatre. Energy Build. 2008, 40, 1334-1343. [CrossRef]

20. Lambert, A.R.; Lin, C.L.; Mardorf, E.; O'shaughnessy, P. CFD simulation of contaminant decay for high Reynolds flow in a controlled environment. Ann. Occup. Hyg. 2010, 54, 88-99. [CrossRef] [PubMed]

21. Handy, R.G.; Jackson, M.; Rodriguez, M.; Goodman, D.; Robinson, G.; Lafreniera, M. The characterization of particles generated and removed during a bone drilling process with surface coated tools. In Proceedings of the 5th International Surface Engineering Conference, Washington State Convention Center, Seattle, WA, USA, 15-17 May 2006; Jackson, M.J., Ed.; ASM International Materials Park: Novelty, OH, USA, 2006; pp. 47-52. 
22. Mei, C.C. 2.7 Aerosols and Coagulation-MIT. Available online: http://www.webcitation.org/archive.php (accessed on 13 April 2016).

23. Yang, L.; Ye, M.; He, B. CFD simulation research on residential indoor air quality. Sci. Total Environ. 2014, 472, 1137-1144. [CrossRef] [PubMed] 